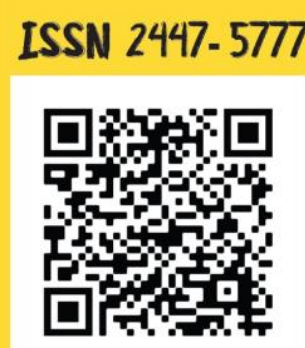

$\varepsilon$

$\mathbf{M}$

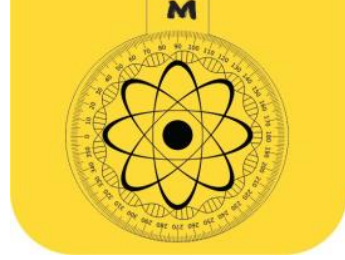

MULTIDISCIPLINARIDADE

Jan. | Jun. 2021 - Volume 7, Número 1, p. 78-90.

\title{
Ensino de História Natural e Biologia: reformas educacionais e programas da escola secundária (1920-1951)
}

\author{
Natural History and Biology Education: educational reforms and secondary \\ school programs (1920-1951)
}

\author{
Maria Cristina Ferreira dos Santos $^{1}$ - https://orcid.org/0000-0003-4522-1109 \\ ${ }^{1}$ Doutora em Educação pela Universidade Federal Fluminense (UFF). Professora Associada na Universidade do \\ Estado do Rio de Janeiro (UERJ), Rio de Janeiro, RJ, Brasil. E-mail: mariacristinauerj@ gmail.com
}

\begin{abstract}
Resumo
Este estudo tem como tema o ensino de Biologia e História Natural, com foco na história dessas disciplinas escolares e nas mudanças educacionais ocorridas nas décadas de 1920 a 1950 no Brasil. O objetivo foi investigar mudanças e continuidades na constituição dessas disciplinas escolares. Foi realizada uma pesquisa documental, utilizando como fontes programas de ensino, legislação e textos da época. Foram analisados programas de ensino oficiais e do Colégio Pedro II, das disciplinas História Natural e Biologia, dos anos de 1920 a 1951, além da legislação e discursos referentes às reformas educacionais. Houve a permanência de conteúdos de Botânica, Zoologia, Geologia e Mineralogia nos programas do ensino secundário de História Natural desse período. No programa de Biologia de 1943, permaneceram conteúdos botânicos e zoológicos e foram excluídos os geológicos e mineralógicos. A disciplina escolar Biologia emergiu nos anos 1930 e foi substituída pela História Natural em 1946, mas conteúdos biológicos permaneceram nos programas de 1936 a 1951. Das "lições" e "pontos práticos" nos programas de 1920-30 às metodologias ativas e experimentais dos anos 1930-50, destaca-se a valorização dos fundamentos científicos e de conhecimentos especializados na história da disciplina escolar Biologia no Brasil.
\end{abstract}

Palavras-chave: Ensino de Biologia e História Natural. Disciplina Escolar. Programas Educacionais. História da Educação em Ciências.

\begin{abstract}
This study has as its theme the Biology and Natural History Education, focusing on these school subjects' history and on educational reforms in the 1920s and 1950s in Brazil. The objective was to investigate changes and continuities in the constitution of these school subjects. A documentary research was carried out, taking as sources educational programs, legislation and other texts. Official educational programs and those of Colégio Pedro II of the school subjects Natural History and Biology from the years 1920 to 1951 and the legislation and discourses related to educational reforms were analyzed. Botany, Zoology, Geology and Mineralogy contents remained in the secondary education programs of Natural History from 1920 to 1951. In the Biology program of 1943 remained
\end{abstract}

Como citar: SANTOS, M. C. F. Ensino de História Natural e Biologia: reformas educacionais e programas da escola secundária (1920-1951). Ensino \& Multidisciplinaridade, v. 7, n. 1, p. 78-90, 2021. 
botanical and zoological contents and geological and mineralogical ones were excluded. The Biology school subject emerged in the 1930s and was replaced by Natural History in 1946, but biological contents were present in the curriculum from 1936 to 1951. From the "lessons" and "practical points" in the 1920-30 programs to the active and experimental methodologies in the 1930s and 1950s, the emphasis on scientific foundations and specialization stands out in the history of science education in Brazil.

Keywords: Biology and Natural History Education. School Subject. Educational Programs. Science Education History.

\section{Introdução}

Nos séculos XVIII e XIX, o debate sobre o ensino secundário na Europa envolveu duas correntes de pensamento: os classicistas, fundamentados nos estudos clássico-humanísticos, e os modernistas, que procuraram substituir e incluir os estudos modernos. Na Alemanha e na Inglaterra, foram criadas instituições voltadas para o ensino científico ao lado de outras de tradição clássico-humanística, e na França foram criados os liceus, em 1802, que tentavam compatibilizar o ensino simultâneo das letras e das ciências. As reformas que se sucederam nos planos de estudos dos liceus franceses no século XIX denotam as disputas nas finalidades de ensino entre a vertente clássico-humanística e a moderna ou científica (VECHIA; LORENZ, 2012).

No Brasil, ao longo dos séculos XIX e XX, travaram-se embates no ensino secundário em relação à predominância dos estudos clássico-humanísticos e científicos. O Imperial Colégio de Pedro II, primeira instituição pública brasileira de ensino secundário, criado em 1837 sob a influência dos liceus franceses e instituído para servir como colégio padrão e "centro difusor das ideias educacionais relativas ao ensino secundário" (VECHIA, 2003, p. 83) no país, adotou um currículo enciclopédico com predominância das humanidades clássicas. Segundo Vechia e Lorenz, outros estabelecimentos de ensino secundário "[...] eram incentivados a adequar o seu currículo e programas aos do Colégio Pedro II, principalmente a partir de 1854, quando os exames preparatórios passaram a ser realizados em conformidade com os programas daquela instituição (1998, p. vii)".

Com a reforma do ensino secundário liderada por Francisco Campos em 1931, a elaboração dos programas desse nível de ensino passou dos professores desse colégio e de ginásios equiparados para comissões designadas pelo ministro da Educação e Saúde Pública, com a centralização do controle do sistema educacional. ${ }^{1}$ Os programas elaborados pelas comissões deveriam ser utilizados em todos os estabelecimentos de ensino secundário e somente nos anos 1950 os professores do Colégio Pedro II voltaram a elaborar os programas, sendo depois perdido definitivamente com a Lei 4.024 de 20 de dezembro de 1961 - Lei de Diretrizes e Bases da Educação (LDB), que não prescreveu um currículo rígido e fixo para todo o território nacional.

A reforma educacional de 1931 instituiu um currículo para o ensino secundário em todo o território nacional, dando maior destaque às disciplinas escolares de ciências em relação às reformas anteriores (LOPES, 2007; DALLABRIDA, 2009; PEDRO, 2014). Em 1942, Gustavo Capanema organizou nova reforma educacional, que valorizou a cultura geral e o ensino de

\footnotetext{
${ }^{1}$ De acordo com o Art. 10 do Decreto N. 19.890 de 1931, os programas e as instruções metodológicas do ensino secundário passaram a ser elaborados pelo Ministério da Educação e Saúde Pública e seriam revistos a cada três anos por comissão designada pelo ministro, e para esta comissão seriam enviadas as propostas da Congregação do Colégio Pedro II.
} 
humanidades, com a diminuição do tempo escolar para as disciplinas de ciências no ensino secundário. Essa organização curricular permaneceu até a Lei 4.024 de 1961, que ampliou a oferta do ensino secundário e não fixou um currículo único para todo o Brasil. De acordo com Souza (2009, 2008), com a LDB de 1961 finalizaram-se os embates entre aqueles que defendiam os estudos das humanidades clássicas e os que privilegiavam os estudos científicos e modernos. A diversificação do currículo e o maior destaque aos últimos são alguns dos sinais da derrota das humanidades no currículo escolar.

Este estudo tem como tema os ensinos de Biologia e História Natural, com foco na história dessas disciplinas escolares nas décadas de 1920 a 1950 no Brasil. A disciplina escolar Biologia se estabeleceu no Brasil no final dos anos 1960 e há poucos estudos sobre as configurações dessa disciplina e da História Natural na primeira metade do século XX, assim como sobre os significados atribuídos a esses construtos disciplinares e a substituição da História Natural pela Biologia no currículo escolar. Com esteio em contribuições teóricas de Goodson (1983, 1995, 1997), Julia (2001, 2002), Chervel (1990) e Viñao (2008), foi realizada uma pesquisa documental, tomando como principais fontes programas de ensino e a legislação educacional no Brasil, com o objetivo de perscrutar mudanças e continuidades na constituição dessas disciplinas escolares no período de 1920 a 1951, e refletir sobre a emergência da Biologia no currículo escolar no período em recorte.

\section{As reformas educacionais e a escola secundária}

As reformas educacionais denotam mudanças em denominações, lugares, tempos, objetivos, conteúdos e/ou métodos de ensino destinados às matérias ou disciplinas. ${ }^{2}$ Neste estudo atentaremos para mudanças e permanências nas disciplinas escolares História Natural e Biologia e apontaremos os ramos do conhecimento incluídos ou excluídos de programas de ensino dessas disciplinas para o ensino secundário. Trataremos inicialmente de aspectos históricos dos anos 1890 aos 1950, período em que a disciplina Biologia emergiu no currículo da escola secundária em dois momentos e de várias reformas no ensino secundário a nível nacional: Benjamin Constant (1890), Epitácio Pessoa (1901), Rivadávia Correa (1911), Carlos Maximiliano (1915), João Luiz Alves (1925), Francisco Campos (1931) e Gustavo Capanema (1942).

Na reforma de $1890,{ }^{3}$ a Biologia - ciência de destaque na filosofia positivista de Augusto Comte - foi incluída no currículo escolar e constituiu-se em marca de mudança da República. Mas, com a morte de Benjamin Constant, em 1891, algumas propostas não se efetivaram. Em 1901, a reforma conhecida como Código Epitácio Pessoa ${ }^{4}$ estabeleceu a formação do bacharel em Ciências e Letras, em um curso com duração de seis anos, e a História Natural nos $5^{\circ}$ e $6^{\circ}$ anos, com duas e cinco aulas semanais respectivamente. Em 1915, o ensino secundário foi reorganizado por Carlos Maximiano e a História Natural perdeu espaço e tempo no currículo escolar: passou a ser oferecida apenas no $5^{\circ}$ e último ano do curso secundário, com três aulas semanais.

Os anos 1920 a 1950 foram cenário de transformações sociais, políticas e econômicas no Brasil, em que o país se afastou da tradição agrário-exportadora e se direcionou para a

\footnotetext{
${ }^{2}$ Neste artigo, as palavras matéria e disciplina foram utilizadas indistintamente.

${ }^{3}$ Cf. Decreto N. 981 - de 8 de novembro de 1890, que aprovou o Regulamento da Instrução Primaria e Secundaria do Distrito Federal (BRASIL, 1890).

${ }^{4}$ Cf. Decreto n. 3.890 de 1/1/1901, do Código dos Institutos Oficiais de Ensino Secundário e Superior (BRASIL, 1901).
} 
urbanização e industrialização. Nos anos 1920, o projeto cultural das elites esteve em debate e questionou-se a legitimidade dos estudos clássico-humanísticos e científicos. Remodelar a escola secundária, para vários educadores, significava adequá-la à modernização da sociedade brasileira, em grande desenvolvimento urbano e industrial (SOUZA, 2008). A reforma de 1925 manteve o currículo literário do ensino secundário e procurou eliminar os exames de preparatórios, determinando a obrigatoriedade da frequência e seriação. Apesar de essa reforma ser uma tentativa para a transformação do ensino secundário pelo governo federal, somente com a reforma de Francisco Campos em 1931 estas mudanças começaram a ser efetivadas (ROMANELLI, 2007).

No primeiro governo de Getúlio Vargas foram estabelecidas duas reformas: a primeira liderada por Francisco Campos (1931) e a segunda por Gustavo Capanema (1942), então Ministros de Educação e Saúde Pública. A reforma educacional de 1931 estendeu-se a todo o território brasileiro, com frequência obrigatória, seriação do ensino secundário, a formação universitária especializada de professores secundários, e maior valorização das ciências no currículo escolar. Na reforma de Campos a organização do ensino secundário foi disposta pelo Decreto $\mathrm{n}^{\mathrm{o}} .19 .890$ de 18 de abril de 1931 e consolidada pelo Decreto $\mathrm{n}^{\mathrm{o}} \cdot 21.241$ de 4 de abril de 1932. O ensino secundário foi dividido em dois cursos seriados: um fundamental, com cinco anos, e outro complementar, com dois anos. O ciclo complementar era obrigatório para os candidatos à matrícula em estabelecimentos de ensino superior ${ }^{5}$. Na exposição de motivos, o ministro afirmou que:

[...] A sua finalidade exclusiva [do ensino secundário] não ha de ser a matrícula nos cursos superiores; o seu fim, pelo contrário, deve ser a formação do homem para todos os grandes setores da actividade nacional, constituindo no seu espírito todo um systema de hábitos, attitudes e comportamento que o habilitem a viver por si mesmo e a tomar, em qualquer situação, as decisões mais convenientes e mais seguras.

[...] A verdadeira educação concentra o seu interesse antes sobre os processos de acquisição do que sobre o objecto que elles teem em vista, e a sua preferência tende não para a transmissão de soluções já feitas, acabadas e formuladas, mas para as direcções do espírito, procurando crear, com os elementos constitutivos do problema ou da situação de facto, a opportunidade e o interesse pelo inquerito, a investigação e o trabalho pessoal em vista da solução própria e adequada e, si possível, individual e nova. (CAMPOS, 1941, p. 47- 48)

Essas palavras enfatizam o ensino secundário com o papel de formação intelectual e moral dos brasileiros, finalidade que também seria priorizada nos programas e metodologias de ensino. Destaca-se vinculação da formação secundária ao desenvolvimento do país, anunciando uma exaltação ao nacionalismo que se acentuaria nos anos seguintes, e a influência do ideário escolanovista em seu discurso, com a valorização do método, do inquérito e da investigação na educação.

A reforma Francisco Campos adotou o currículo de liceus científicos, distribuindo de maneira mais equilibrada as Humanidades e matérias científicas, e estabeleceu os estudos regulares, o currículo seriado e a frequência obrigatória, influenciando a profissionalização dos professores secundários no Brasil (ROMANELLI, 2007; SOUZA, 2008). Nessa reforma foi destinada maior carga horária para as disciplinas escolares de Ciências - Ciências Físicas e

\footnotetext{
5 Aqueles que pretendiam ingressar no curso jurídico cursavam a disciplina Biologia Geral na $1^{\mathrm{a}}$ série e os candidatos aos cursos superiores de Medicina, Odontologia e Farmácia ou de Engenharia e Arquitetura cursavam a disciplina História Natural na $1^{\mathrm{a}}$ e $2^{\mathrm{a}}$ séries do complementar.
} 
Naturais, História Natural, Física e Química - com 23 tempos de aulas semanais, do que nas anteriores: 21 tempos na Reforma João Luiz Alves (1925), 17 tempos na Reforma Epitácio Pessoa (1901) e 9 tempos na Reforma Carlos Maximiliano (1915). Entretanto, mesmo com essa distribuição, o tempo previsto para as Ciências e Matemáticas no curso secundário era inferior ao das Humanidades (LOPES, 2007).

Dallabrida (2009) ressalta a intenção de que os alunos frequentassem as aulas em uma determinada instituição de ensino secundário e não em vários liceus ou ginásios, de forma a impedir que continuasse o ensino avulso, como no regime de preparatórios e exames parcelados. Foram várias as dificuldades enfrentadas para sua implantação e o ensino secundário continuava a ser uma educação para a elite, com o enciclopedismo dos programas e os cinco anos necessários para a formação geral (NUNES, 1962).

Em 1942, no Estado Novo, o então Ministro de Educação e Saúde Gustavo Capanema iniciou as reformas de ensino nos níveis primário e secundário, com a publicação das "Leis Orgânicas do Ensino" até 1946. A Lei Orgânica do Ensino Secundário 6 manteve os sete anos de duração do ensino secundário, modificando os ciclos: o primeiro ciclo de quatro anos de duração, denominado ginasial, que tinha a finalidade anunciada de dar as noções básicas deste nível aos alunos, e que incluía a disciplina Ciências Naturais na terceira e quarta séries; e o segundo ciclo com três anos, que se dividia em dois cursos paralelos - clássico e científico, sendo a disciplina Biologia comum a ambos. Na exposição de motivos, Gustavo Capanema afirmou que o ensino secundário deveria formar a consciência humanística e a consciência patriótica, através de estudos da língua nacional, da História do Brasil e da Geografia do Brasil (MEC, 1952). O ensino secundário permaneceu com o objetivo de preparo para o ingresso no ensino superior e os cursos ginasial e colegial caracterizavam-se pela valorização da cultura geral e predominância do enciclopedismo, com a diminuição do tempo escolar para as disciplinas de ciências e aumento do tempo das disciplinas de humanidades.

A Reforma Capanema revalorizou o ensino de humanidades e deu ênfase no nacionalismo no ensino secundário, com intenção de formação de uma elite católica e de formação clássica, mas não modificou significativamente a estrutura do ensino secundário. Nos anos 1930 e 1940, a autonomia dos Estados nas decisões sobre o ensino secundário foi anulada pela centralização das decisões sobre a organização do ensino, a elaboração de programas e seleção de livros didáticos pelo Estado, continuando o governo federal a ter o controle sobre as escolas de ensino secundário em todo o território nacional.

Para Gomes (2003), as políticas educacionais de 1930-1945 devem ser compreendidas em um contexto ampliado de políticas sociais, incluindo a educação escolar, as políticas culturais e a educação popular. As políticas sociais deste período centravam-se em três pontos fundamentais: trabalho, família e educação. A educação foi pensada em sentido amplo, como meio para a transformação do povo brasileiro e, após o golpe de 1937, anunciou-se o ideal de justiça social através do trabalho e da educação. Neste discurso de legitimação que se construiu no Estado Novo, o trabalho era visto como uma atividade que dignificava o homem e que o integrava à sua sociedade, uma forma de cumprimento dos deveres com a pátria. A educação era peça fundamental desta engrenagem, pois só através dela se entendia possível formar um povo genuinamente brasileiro, através da inculcação de valores como a nacionalidade, a disciplina, a moral, o trabalho e a família, para formar a "consciência patriótica" e moldar os indivíduos para servir à nação (ibidem, 2003).

${ }^{6}$ Cf. Decreto-Lei 4244 de 9 de abril de 1942 - Lei Orgânica do Ensino Secundário. 


\section{A história das disciplinas escolares Biologia e História Natural}

As pesquisas na história das disciplinas escolares têm contribuições de autores como Andrè Chervel (1990), Dominique Julia (2001, 2002), Ivor Goodson (1983, 1995, 1997) e Antonio Viñao (2008), com estudos sobre as culturas escolares e a construção socio-histórica das disciplinas. Ao investigar a história de uma disciplina escolar, Viñao (2008) assinala a importância de aguçar o olhar para: 1) o lugar, presença, denominações e importância da disciplina nos planos de estudos; 2) objetivos e discursos que validam a disciplina escolar; 3) os conhecimentos prescritos; 4) o perfil dos professores das disciplinas; e 5) o estudo de práticas e atividades escolares. É importante examinar esses fatores, considerando o contexto sóciohistórica e as relações entre as disciplinas escolares, as ciências de referência e as finalidades sociais.

Chervel (1990) e Julia (2001, 2002) ressaltam que as disciplinas escolares não são a simples vulgarização ou adaptação das ciências de referência, mas sim uma construção particular da escola. Chervel (1990, p. 180) afirma que as disciplinas são “[...] independentes, numa certa medida, de toda realidade cultural exterior à escola" e Julia (2002) enfatiza as finalidades e conteúdos das matérias escolares, destacando que os saberes escolares não são mera simplificação daqueles oriundos das ciências de referência, e são elaborados na escola.

No estudo da história das disciplinas escolares, Goodson $(1983,1997)$ recomenda compreender a constituição das disciplinas escolares pela interpretação das fontes e análise das tendências e transformações que ocorreram nos objetivos, conteúdos e métodos de ensino e ressalta a importância dos sujeitos e grupos sociais envolvidos na sua constituição. Goodson (1995, p. 210) considera o currículo escrito "um dos melhores roteiros oficiais para a estrutura institucionalizada da escolarização". Este autor propõe a investigação das tradições disciplinares, entendendo-as como categorias que podem contribuir para a compreensão das permanências e mudanças nas disciplinas escolares: pedagógicas - relacionadas às necessidades dos alunos no processo de ensino e aprendizagem; utilitárias - relacionadas ao cotidiano dos alunos e à formação para o mercado de trabalho; e acadêmicas - relacionadas à continuidade dos estudos, preparação para exames e formação e pesquisa nas universidades.

No que tange à história da disciplina escolar Biologia em países de língua inglesa, estudos indicam que o período compreendido entre o final do século XIX e os anos 1960 foi significativo para a investigação dos processos que contribuíram para a sua constituição. Tracey (1962) analisou, em escolas na Grã-Bretanha entre os anos de 1900 e 1960, fatores sociais e econômicos que contribuíram para o aumento do prestígio da disciplina escolar Biologia, substituindo a Botânica e a Zoologia, que integravam o currículo escolar como disciplinas isoladas. Goodson $(1995,1997)$ faz referência à Zoologia e Botânica como disciplinas isoladas coexistindo com a Biologia Geral até os anos 1960 em escolas inglesas. Em escolas norteamericanas, a disciplina História Natural existia desde antes da disciplina escolar Biologia. No final do século XIX a Botânica, a Zoologia e a Fisiologia Humana eram disciplinas separadas e a última tinha grande popularidade. No primeiro quartel do século XX, a Fisiologia Humana perdeu importância e a Biologia se fortaleceu no ensino secundário. Neste período, nos Estados Unidos, o afluxo de imigrantes e a ampliação da industrialização levaram a novas demandas de escolaridade e de inclusão social do corpo discente. Estes fatores, associados à ampliação do prestígio das Ciências Biológicas frente a outras Ciências, contribuíram para que a Biologia passasse de uma posição secundária para outra central no currículo escolar (ROSENTHAL; BYBEE, 1987).

No Brasil, poucos estudos sobre a história do ensino de ciências foram realizados com recorte temporal antes dos anos 1950. Krasilchik (1987), na periodização da história do ensino 
de ciências no Brasil, toma como marco inicial a década de 1950. Essa periodização se tornou hegemônica, mas não coaduna com o que outros estudos apontam (ERN; AIRES, 2007; SANTOS, 2013). Existem poucos estudos sobre as disciplinas escolares História Natural e Biologia em períodos anteriores à década de 1950 no Brasil. Segundo Santos (2013), a disciplina História Natural foi estabelecida no ensino secundário no Brasil desde o século XIX ao final dos anos 1960, quando foi definitivamente substituída pela Biologia. A disciplina escolar Biologia emergiu em dois períodos nos programas de ensino do Colégio Pedro II: anos 1890 e 1930-40 (SANTOS, 2013). É para o segundo período que esse estudo se debruça, com o objetivo de compreender como foram estabelecidas e organizadas essas duas disciplinas, com base na análise de programas de ensino, legislação e textos da época.

\section{Os programas de História Natural e Biologia para a escola secundária}

Durante o Império, o Colégio Pedro II adotou um currículo enciclopédico com predominância das humanidades clássicas sobre as matérias de ciências, que estavam em menor número e condensadas, e seus planos de estudo e os de ginásios equiparados foram instituídos como modelares para o ensino secundário no Brasil (VECHIA; LORENZ, 2012; VECHIA, 2003). O currículo do Colégio Pedro II, quando implantado em 1837, teve como modelo os currículos dos liceus franceses, caracterizados pela tradição disciplinar acadêmica (VECHIA, 2003). A influência francesa também esteve presente nos livros indicados para ensino das disciplinas escolares de ciências, a maioria de autores estrangeiros franceses ou de professores do Colégio (LORENZ, 2010). O enciclopedismo acompanhou este Colégio mesmo após a República, quando foram acrescentadas as ciências segundo a ordem de classificação da filosofia positivista de Augusto Comte. Esta valorizava a técnica e defendia uma escola laica, com a inclusão de disciplinas ditas científicas, como a Matemática, Astronomia, Física, Química, Biologia, Sociologia e Moral, para romper com a tradição pedagógica católica - humanista (COMTE, 1978).

Em relação à presença, denominação e ao lugar que a História Natural e a Biologia ocuparam no currículo do Colégio Pedro II, e possivelmente em outras instituições de ensino secundário no Brasil que o tomaram como modelar, os programas e a legislação foram as principais fontes. $\mathrm{Na}$ análise dos programas procedeu-se também à divisão dos conteúdos de ensino em ramos do conhecimento. Não se pretendendo conclusiva, esta abordagem possibilita uma aproximação inicial às perspectivas disciplinares da História Natural e Biologia no período em recorte. $\mathrm{Na}$ análise dos dados, foram destacados como ramos de conhecimento das disciplinas escolares em estudo: Botânica, Zoologia, Geologia, Mineralogia, Higiene e Ramo Biológico ${ }^{7}$.

De 1920 a 1934, no currículo do Colégio Pedro II a disciplina História Natural esteve presente nos $4^{\circ}$ e $5^{\circ}$ anos do ensino secundário, não se tendo conhecimento de uma disciplina com a denominação de Biologia, mesmo após a criação dos cursos complementares na reforma de 1931. Os programas de ensino do $4^{\circ}$ e $5^{\circ}$ anos para os anos de 1920 a 1930 apresentavam "lições" organizadas nos ramos de Botânica, Zoologia, Geologia e Mineralogia. Alguns itens das poucas "lições" da parte inicial dos programas, denominada "Parte Geral", tratavam de conceitos do Ramo Biológico, tais como: "da experimentação em Biologia" e "Theorias cellular e protoplasmatica", mas não se consistiam em ramo a ser ensinado na disciplina. De acordo

\footnotetext{
${ }^{7}$ Neste estudo, foram utilizados os termos História Natural, Biologia e Biologia Geral para as disciplinas escolares, conforme legislação e/ou programas, e Ramo Biológico para a designação de um dos ramos de conhecimento dessas disciplinas.
} 
com o Decreto n. 11.530 de 18 de março de 1915, cada "curso" (disciplina) deveria ter "80 lições", os programas deveriam ser impressos e designar as atividades a serem realizadas nas "lições". Nos programas de História Natural dos anos de 1920, 1921, 1922 e 1924 existiam 80 "lições" no $4^{\circ}$ e $5^{\circ}$ anos, com respectivamente 17 e 15 "pontos práticos" (COLÉGIO PEDRO II, 1920; 1921; 1922; 1924). Após o Decreto No 16.782 A de 13 de janeiro de 1925, na reforma João Luiz Alves, a disciplina História Natural permaneceu no currículo do Colégio Pedro II no $4^{\circ}$ e $5^{\circ}$ anos. Nos programas de 1925 e 1926 permaneceram 80 "lições" em cada um deles, com 17 "pontos práticos" no $4^{\circ}$ ano e 15 no $5^{\circ}$ ano. Nos programas para os anos de 1929 de 1930 o número de "lições" foi reduzido e 17 e 15 "pontos práticos" foram mantidos no $4^{\circ}$ e $5^{\circ}$ anos (COLÉGIO PEDRO II, 1929; 1930).

Após a reforma de 1931, a disciplina História Natural era obrigatória e deveria ser ofertada na $3^{\mathrm{a}}, 4^{\mathrm{a}}$ e $5^{\mathrm{a}}$ séries do ciclo fundamental do ensino secundário em todos os estabelecimentos de ensino secundário. No Curso Complementar, a disciplina Biologia Geral foi prevista para os candidatos ao ingresso em cursos superiores na área jurídica e a disciplina História Natural para o ingresso em cursos superiores de Medicina e Engenharia, entre outros. Os programas oficiais de História Natural abordavam conteúdos de ensino de Botânica, Zoologia, Mineralogia e Geologia nas $3^{\mathrm{a}}, 4^{\mathrm{a}}$ e $5^{\mathrm{a}}$ séries e, nesta última, também História da Terra. Em 1934, os programas do Colégio Pedro II em vigor na terceira e quarta séries foram os expedidos pelo Ministério de Educação e Saúde em 1931, mas na quinta e sexta séries vigoraram os programas aprovados pela Congregação do Colégio para o ano de 1930 e não os oficiais (COLÉGIO PEDRO II, 1934, p.5 e 57).

A Lei Orgânica de 1942 elencou no currículo do ensino secundário a disciplina escolar Biologia e em 12 de março de 1946 o Decreto-Lei N. 9.054 substituiu-a pela História Natural. No programa de Biologia de 1943, além da presença de conteúdos do Ramo Biológico, permaneceram a Botânica e Zoologia, houve a exclusão da Mineralogia e da Geologia e a inclusão da Higiene.

Em 1945 Gustavo Capanema deixa o Ministério e assume Ernesto de Sousa Campos (1882-1970), que expede a Portaria Ministerial no. 244 em 25 de março de 1946, com programas de História Natural para o curso colegial. Estes se referiam aos cursos clássico e científico do ensino secundário e reuniam os ramos de Botânica, Zoologia, Mineralogia, Geologia e o ramo Biológico (Quadro 1), sem conteúdos de Higiene (MEC/INEP, 1955). Em 1951 outros programas foram expedidos, com a inclusão de conteúdos de Higiene dentro da História Natural e organização diferente dos ramos no Curso Clássico em relação aos programas de 1946, mas mantendo-se a distribuição da disciplina História Natural na $2^{\mathrm{a}}$ e $3^{\mathrm{a}}$ séries.

Quadro 1 - Ramos da História Natural e Biologia nos programas oficiais do ensino secundário (1931, 1936, 1943, 1946, 1951) e do Colégio Pedro II (1920 - 1930, 1934)

\begin{tabular}{c|c|l|l|l|l|c|l}
\hline $\begin{array}{c}\text { Ano do } \\
\text { Programa }\end{array}$ & Matérias/Disciplinas & Botânica & Zoologia & $\begin{array}{c}\text { Mineral } \\
\text { ogia }\end{array}$ & Geologia & $\begin{array}{c}\text { Ramo } \\
\text { Biológico }\end{array}$ & Higiene \\
\hline $1920-30$ & História Natural & & & & & noções & \\
\hline 1931 & $\begin{array}{c}\text { História Natural } \\
\left(3^{\mathrm{a}}, 4^{\mathrm{a}} \text { e } 5^{\mathrm{a}} \text { séries }\right)\end{array}$ & & & & & & \\
\hline 1934 & $\begin{array}{c}\text { História Natural } \\
\left(3^{\mathrm{a}}, 4^{\mathrm{a}} \mathrm{e} 5^{\mathrm{a}} \text { séries) }\right.\end{array}$ & & & & & & \\
\hline \multirow{2}{*}{1936} & $\begin{array}{c}\text { História Natural } \\
\text { (Curso Complementar) }\end{array}$ & & & & & & \\
\cline { 2 - 7 } & $\begin{array}{c}\text { Biologia Geral } \\
\text { (Curso Complementar) }\end{array}$ & & & & & & \\
\hline
\end{tabular}




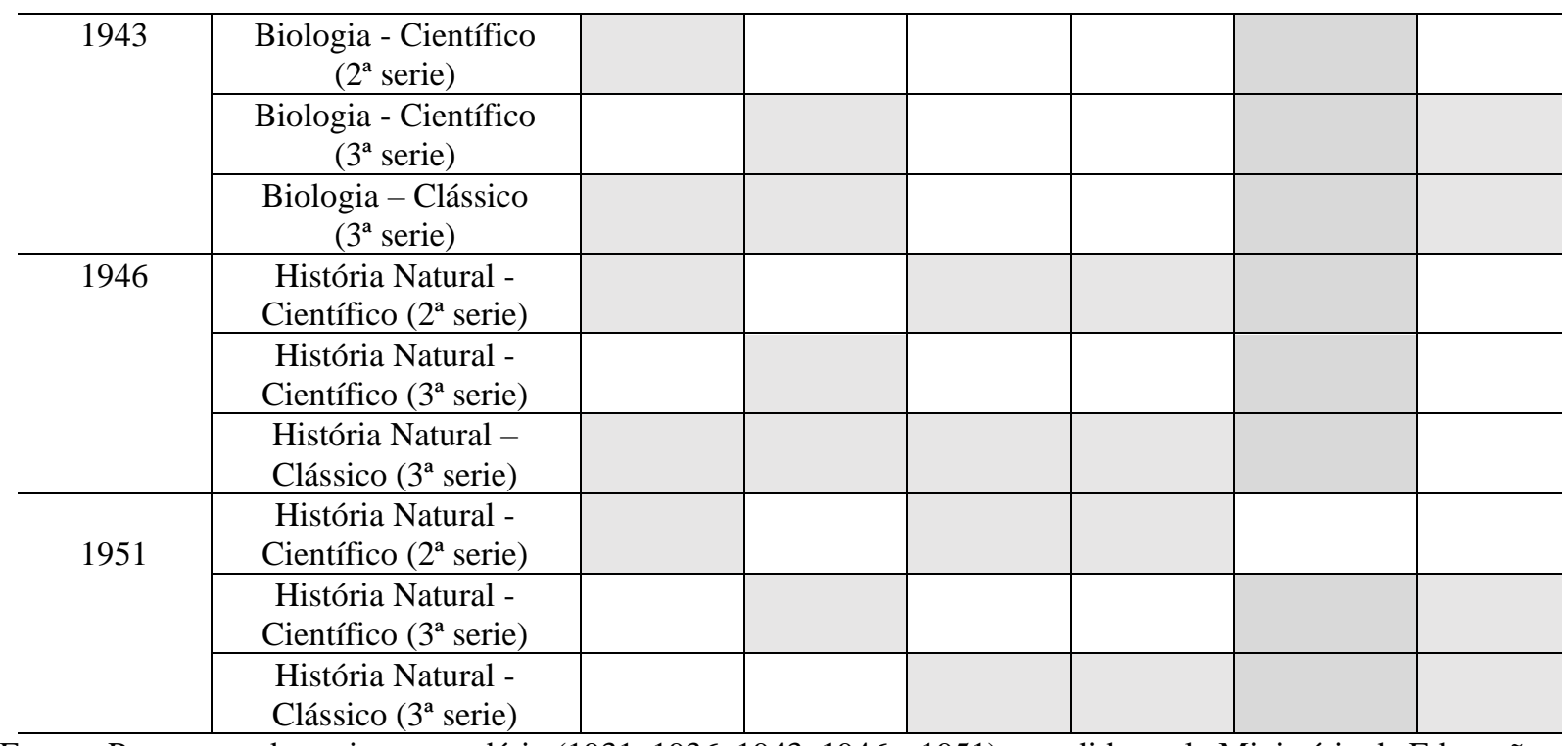

Fontes: Programas do ensino secundário (1931, 1936, 1943, 1946 e 1951) expedidos pelo Ministério da Educação e Saúde e programas de ensino do Colégio Pedro II de 1920 a 1930 e 1934.

Em estudos sobre a história das disciplinas escolares, Juliá (2002) e Viñao (2008) ressaltam a importância da presença, lugar, denominações, carga horária e conteúdos da disciplina. Neste estudo aponta-se que a disciplina História Natural passou por mudanças na legislação e programas de ensino de 1920 a 1951 em relação à sua distribuição nas séries e horas de aulas semanais, mas conteúdos de Botânica, Zoologia, Mineralogia e Geologia permaneceram nos programas. A Geologia e a Mineralogia foram ramos da disciplina escolar História Natural, junto com a Zoologia e a Botânica, na maioria dos programas do Colégio Pedro II no período de 1920-1951. No programa de 1943, em que foi estabelecida a Biologia como disciplina escolar, substituindo a História Natural, estes dois ramos - Mineralogia e Geologia - foram excluídos da Biologia, o que não significa que tenham sido excluídos do currículo, pois os conteúdos podem ter sido incorporados a outras disciplinas. Diferentemente do que ocorreu em escolas inglesas, em que a Zoologia, Botânica e Biologia Geral foram disciplinas isoladas até a década de 1960 (GOODSON, 1995, 1997), nos programas de ensino oficiais e do Colégio Pedro II havia a previsão de apenas uma disciplina - História Natural ou Biologia - reunindo conteúdos desses três ramos.

A disciplina escolar Biologia emergiu nos anos 1930, substituiu a História Natural no programa oficial de 1943 e foi substituída pela História Natural em 1946, mas conteúdos biológicos estiveram presentes nos programas educacionais de 1936 a 1951, além de noções gerais de Biologia Geral nos programas de 1920-30. A emergência da disciplina Biologia na década de 1940 no currículo escolar pode ser compreendida relacionada ao desenvolvimento das ciências de referência. No século XX houve grande avanço da Bioquímica e da Biologia Molecular (JACOB, 1983) e as Ciências Biológicas se fortaleceram e conquistaram o reconhecimento como uma ciência unificada, com forte base experimental e matematização. A consolidação dos conhecimentos relativos ao estudo dos seres vivos em uma única disciplina escolar ocorreu no Brasil no final dos anos 1960, quando a Biologia substituiu definitivamente a História Natural (SANTOS, 2013).

Em programas do ensino secundário de Biologia de 1943 e de História Natural de 1951 foram incorporados conteúdos de Higiene. Essa inclusão nos programas pode ter sido influenciada pelo campo das ciências médicas, sendo necessários outros estudos para subsidiar a compreensão destas mudanças no construto disciplinar. 
O estudo da história dessas duas disciplinas escolares indica mudança de uma vertente humanitária para científica, articulada também ao desenvolvimento das ciências da educação da época. Em relação aos modos de ensinar, as "lições" e "pontos práticos" nos programas de 1920-30 são reconfigurados em métodos ativos e experimentais nos discursos dos anos 1930 a 1950, acentuando-se a valorização de uma educação com base científica e especialização das áreas de conhecimento (SANTOS, 2013), como também apontado em estudos realizados em países de língua inglesa (TRACEY, 1962; ROSENTHAL; BYBEE, 1987).

\section{Considerações finais}

Os programas de História Natural e Biologia do ensino secundário sofreram mudanças entre os anos de 1920 e 1951, com a permanência de conteúdos da Botânica e da Zoologia, ramos tradicionais da História Natural, na maioria dos programas. Houve a exclusão da Geologia e Mineralogia no programa de 1943, a previsão de oferta das disciplinas Biologia Geral e Biologia nos anos 1930-40 e programas com conteúdos biológicos nos anos de 1936 a 1951. No período de 1920 a 1951, noções ou conteúdos de Biologia estavam presentes nos programas do ensino secundário de História Natural e Biologia, e conteúdos de Mineralogia e Geologia somente nos programas da disciplina História Natural.

Argumenta-se que as modificações nos programas de ensino de História Natural e Biologia na primeira metade do século XX sinalizam sua gradual reconfiguração, sob a influência do desenvolvimento das Ciências Biológicas desde o final do século XIX e das finalidades pedagógicas e sociais da educação escolar. Se a organização de conhecimentos da Biologia e da História Natural se configura em uma única disciplina no ensino secundário no Brasil, diferenciando-se daquela em disciplinas isoladas na primeira metade do século XX em países de língua inglesa, de outro modo os construtos disciplinares convergem no que diz respeito à valorização da Biologia no currículo escolar na primeira metade do século XX.

Este estudo contribui para a compreensão da construção socio-histórica da disciplina escolar Biologia, com a permanência de conteúdos biológicos e a exclusão de conteúdos geológicos e mineralógicos nos programas e legislação educacional brasileira no período de 1920-1951. São relevantes outros estudos para compreendermos significados e tradições atribuídos aos dois construtos disciplinares e a consolidação da Biologia no currículo escolar.

\section{Referências}

\section{Fontes Primárias}

ATUALIDADES PEDAGÓGICAS. Programas do Ensino Secundário (em vigor em março de 1950). Suplemento n.1 da Revista Atualidades Pedagógicas. São Paulo: Ed. Companhia Nacional, 1950.

BRASIL. Decreto n. 3.890 de 1/1/1901, do Código dos Institutos Oficiais de Ensino Secundário e Superior.

BRASIL. Decreto $N^{0} 16.782$ A, de 13 de Janeiro de 1925. Estabelece o concurso da União para a difusão do ensino primário, organiza o Departamento Nacional do Ensino, reforma o ensino secundário e o superior e dá outras providências. História da Educação, ASPHE/FaE/UFPel, Pelotas, v. 13, n. 28 p. 253-290, Maio/Ago. 2009. 
BRASIL. Decreto n. 19.890, de 18 de abril de 1931. Dispõe sobre a organização do ensino secundário. Disponível em:

<https://legis.senado.leg.br/norma/437916/publicacao/15621228>. Acesso em: 15 out. 2021.

BRASIL. Decreto n. 21.241, de 4 de abril de 1932. Consolida as disposições sobre a organização do ensino secundário e dá outras providências. Disponível em:

$<$ https://www2.camara.leg.br/legin/fed/decret/1930-1939/decreto-21241-4-abril-1932-

503517-publicacaooriginal-81464-pe.html >. Acesso em: 5 nov. 2021.

BRASIL. Decreto-lei N. 4.244 de 9 de abril de 1942. Lei orgânica do ensino secundário. Disponível em: < https://legis.senado.leg.br/norma/529330/publicacao/15710770>. Acesso em: 21 out. 2021.

BRASIL. Decreto-lei n. 9.054, de 12 de março de 1946. Substitui a disciplina Biologia pela de História Natural da Lei Orgânica do Ensino Secundário. Disponível em:

<https://www2.camara.leg.br/legin/fed/declei/1940-1949/decreto-lei-4244-9-abril-1942-

414155-publicacaooriginal-1-pe.html >. Acesso em: 14 out. 2021.

BRASIL. Decreto-Lei 8530 de 02/01/1946 - Lei Orgânica do Ensino Normal. Das bases da organização do ensino normal. Disponível em:

<https://www2.camara.leg.br/legin/fed/declei/1940-1949/decreto-lei-8530-2-janeiro-1946-

458443-publicacaooriginal-1-pe.html >. Acesso em: 5 nov. 2021.

CAMPOS, F. Educação e Cultura. Rio de Janeiro, Livraria José Olympio Editora, 1941. $2^{\mathrm{a}}$ ed. 202 p.

COLEGIO PEDRO II. Programmas de ensino do Collegio Pedro II para o anno de 1920. Rio de Janeiro: Typ. Revista dos Tribunaes, 1920.

COLEGIO PEDRO II. Programmas de ensino do Collegio Pedro II para os annos de 1921, 1922 e 1924. Rio de Janeiro: Typ. Revista dos Tribunaes, 1921, 1922 e 1924.

COLEGIO PEDRO II. Programmas de ensino do Collegio Pedro II para o anno de 1927. Rio de Janeiro: Pap. Americana, Assembléa 90, 1927.

COLEGIO PEDRO II. Programmas de ensino do Collegio Pedro II para o anno de 1928. Rio de Janeiro, Typ. d’Encadernadora, Rua São José, 35.

COLEGIO PEDRO II. Programmas de ensino do Collegio Pedro II para o anno de 1929. Rio de Janeiro: Imprensa Nacional, 1929.

COLEGIO PEDRO II. Programmas de ensino do Collegio Pedro II para o anno de 1930. Rio de Janeiro: Imprensa Nacional, 1930.

COLÉGIO PEDRO II. Programas. Rio de Janeiro: Gráfica Nacional Editora, 1934.

DEPARTAMENTO NACIONAL DO ENSINO. Programmas de ensino do Collegio Pedro II para o anno de 1925. Rio de Janeiro, Typ. Revista dos Tribunaes, 1925. 
DEPARTAMENTO NACIONAL DO ENSINO. Programmas de ensino do Collegio Pedro II para o anno de 1926. Rio de Janeiro, Typ. d’Encadernadora, Rua São José, 35, 1926.

\section{Bibliografia}

CHERVEL, A. História das disciplinas escolares: reflexões sobre um campo de pesquisa. Teoria e Educação, n. 2, Porto Alegre, 1990, p. 177-229.

COMTE, A. Curso de filosofia positiva (Coleção Os pensadores). São Paulo: Abril Cultural, 1978.

DALLABRIDA, N. A reforma Francisco Campos e a modernização nacionalizada do ensino secundário. Educação, Porto Alegre, v. 32, n. 2, p. 185-191, maio/ago. 2009.

ERN, E.; AIRES, J. A. Contribuições da História das Disciplinas Escolares para a História do Ensino de Ciências. Educação \& Realidade, vol. 32, n. 1, enero-junio, 2007, p. 91-108.

GOMES, A. C. O Primeiro Governo Vargas: projeto político e educacional. In: MAGALDI, Maria; ALVES, Cláudia; GONDRA, José Gonçalves (org.). Educação no Brasil: história, cultura e política. Bragança Paulista: EDUSF, 2003. p. 445- 462.

GOODSON, I. F. School Subjects and Curriculum Change. Croom Helm Curriculum Policy and Research Series, 1983.

GOODSON, I. F. Currículo: Teoria e História. Petrópolis: Vozes, 1995.

GOODSON, I. F. A Construção Social do Currículo. Coletânea de textos de Goodson organizada por Antônio Nóvoa. Lisboa: Educa, 1997.

JACOB, F. A Lógica da Vida: uma história da hereditariedade. Rio de Janeiro: Edições Graal, 1983.

JULIA, D. A cultura escolar como objeto histórico. Revista Brasileira de História da Educação v.1, n. 1, Campinas, jan./jun. 2001, p. 9-43.

JULIA, D. Disciplinas escolares: objetivos, ensino e apropriação. In: LOPES, A. C. R.; MACEDO, E. (Org.) Disciplinas e integração curricular: história e políticas. Rio de Janeiro: DP \& A, 2002.

KRASILCHIK, M. O Professor e o Currículo das Ciências. São Paulo: Edusp, 1987.

LORENZ, K. M. Ciência, Educação e Livros Didáticos do Século XIX. Os compêndios de Ciências Naturais do Colégio Pedro II. Uberlândia: EDUFU, 2010.

MINISTÉRIO DA EDUCAÇÃO E CULTURA/INSTITUTO NACIONAL DE ESTUDOS PEDAGÓGICOS. A Educação Secundária no Brasil. Publicação no. 9. Companhia de Inquéritos e Levantamentos do Ensino Médio e Elementar, 1955.

MINISTÉRIO DA EDUCAÇÃO E SAÚDE. Ensino Secundário no Brasil. Publicação no. 67. INEP, 1952. 
NUNES, M. T. Ensino secundário e sociedade brasileira. Rio de Janeiro: Instituto Superior de Estudos Brasileiros, 1962.

PEDRO, R. T. História da equiparação do Colégio Marista Arquidiocesano de São Paulo ao Colégio Pedro II (1900-1940). 2014.175 f. Dissertação (Mestrado em Educação) Faculdade de Educação, Pontifícia Universidade Católica de São Paulo, São Paulo, 2014.

ROMANELLI, O. O. História da educação no Brasil (1930/1973). 31ª ed. Petrópolis, RJ: Vozes, 2007.

ROSENTHAL, D. B.; BYBEE, R. W. Emergency of the Biology curriculum: a science of life or a science of living? In: POPKEWITZ, T. The Formation of School Subjects: the Struggle for Creating an American Institution. London: Falmer Press, 1987, p. 123-144.

SANTOS, M. C. F. A Biologia de Candido de Mello Leitão e a História Natural de Waldemiro Alves Potsch: professores autores e livros didáticos conhecimento e poder em disputa na constituição da Biologia escolar (1931 - 1951). Tese (Doutorado em Educação) Faculdade de Educação, Universidade Federal Fluminense, Niterói, 2013.

SOUZA, R.F. História da Organização do Trabalho Escolar e do Currículo no Século XX. São Paulo: Cortez Editora, 2008.

SOUZA, R. F. A renovação do currículo do ensino secundário no Brasil: as últimas batalhas pelo humanismo (1920-1960). Currículo sem fronteiras, v. 9, 2009, p. 72-90.

TRACEY, G.W. Biology - its struggle for recognition in English Schools during the period 1900-1960. The School Science Review, 93, 1962, p. 423-433.

VECHIA, A. Imperial Collegio de Pedro II no século XIX: portal dos estudos históricos franceses no Brasil. In: VECHIA, A. \& CAVAZOTTI, M. A. (Org.) A Escola Secundária: modelos e planos. São Paulo: Annablume, 2003, p. 25-35.

VECHIA, A.; LORENZ, K. M. O Imperial Collegio De Pedro II, propagador de ideias educacionais francesas para seus congêneres em todo o Brasil. In: MOGARRO, M.J.; CUNHA, M.T.S. (orgs.) Rituais, Espaços \& Patrimónios Escolares. IX Congresso Luso Brasileiro de História da Educação (Atas). Lisboa: Instituto de Educação da Universidade de Lisboa, 2012. p. 31-42.

VECHIA, A.; LORENZ, K. M. Programas de ensino da escola secundária brasileira. Curitiba: Ed. Autores, 1998.

VIÑAO, A. A história das disciplinas escolares. Revista Brasileira de História da Educação, n.18, set/dez. 2008, p. 174-214. 